\title{
ENERGY METABOLISM AND PRODUCTIVITY OF FARM ANIMALS DURING ADAPTATION TO HIGH AIR TEMPERATURE
}

\author{
Lyudmila K. Buslovskaya $^{1^{*}}$, Alexey Yu. Kovtunenko ${ }^{1}$

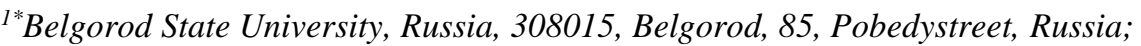 \\ *Corresponding Author Lyudmila K. Buslovskaya, e-mail: Buslovskaya@ bsu.edu.ru;
}

Received August 2021; Accepted September 2021; Published October 2021;

DOI: https://doi.org/10.31407/ijees11.443

\begin{abstract}
The unproductive energy consumption of calf bulls and chickens of different breeds and ages increased by $27 \%$ on average. This affected the efficiency of production, which significantly decreased. Black-and-white calf bulls have adapted to the air temperature of $38{ }^{\circ} \mathrm{C}$ with a great stress of physiological mechanisms, and, therefore, with large energy costs. Heat production among red steppe calf bulls increased maximally by $2.7 \mathrm{MJ}$, black-and-white calf bulls - by $5.7 \mathrm{MJ}$, which amounted to $18 \%$ and $42 \%$, respectively. The growth energy with the same demand for exchange energy decreased by $3.5 \mathrm{MJ}$ on average. At an air temperature of $28-30{ }^{\circ} \mathrm{C}$, the consumption of mixed feed by hens decreased, the gross feed energy decreased by $12 \%$ on average. A significant part of the metabolic energy ( $23.6 \mathrm{~kJ}$ per $100 \mathrm{~g}$ of live weight) was released by hens in the form of heat, i.e., unproductively. The exchange energy by head per day was $951 \mathrm{~kJ}$ and turned out to be $18 \%$ less than at normal air temperature. The energy of sediments by head per day decreased by $25 \%$, the average daily gain in live weight made $3 \mathrm{~g}$ on average. Thus, the preservation of thermal homeostasis in the body of calf bulls and chickens during adaptation to high air temperatures was achieved due to unproductive energy consumption increase and productivity decrease. In order to preserve the health and high productivity of animals during their maintenance and energy nutrition rationing, it is necessary to take into account the increase in unproductive energy consumption for the restoration of homeostasis and adaptation to the ambient temperature.
\end{abstract}

Key words: chickens, calf bulls, high air temperature, energy metabolism, productivity. 